\title{
Observatório de Mídia e Cidadania: interações entre a reflexão acadêmica e a sociedade midiatizada
}

\section{Centre for Media and Citizenship: interactions between academic reflection and the mediatized societ}

\author{
Simone Antoniaci Tuzzo ${ }^{1}$ \\ (simonetuzzo@hotmail.com) \\ Tiago Mainieri de Oliveira ${ }^{2}$ \\ (tiagomainieri@hotmail.com) \\ Magno Medeiros ${ }^{3}$ \\ (magno.ufg@gmail.com) \\ Adriana Moraes, Eva Ribeiro, Francislanda Penha, Gabriella Souza, Kamila Vieira, Kelly Ruas e Núbia Simão ${ }^{4}$ \\ http://dx.doi.org/10.5216/cei.v14i1.21495
}

\begin{abstract}
Resumo
Enquanto construtora de identidades coletivas, a mídia tem papel fundamental na história da sociedade brasileira. Por meio de signos e sinais, constrói e transforma imagens e realidades. Imprescindível para a conquista da república e a consolidação do capitalismo, ela desafia a comunidade científica interessada a entender seus reflexos sobre a sociedade. Nesse processo, o receptor não é apenas espectador passivo, mas um usuário crítico que ressignifica e transforma as mensagens midiáticas. Com o objetivo de monitorar a mídia, desvendar as relações entre esta e a sociedade, promovendo um diálogo entre mídia e esfera pública, alunos e professores da linha Mídia e Cidadania do mestrado em Comunicação da Facomb/UFG criaram o Observatório de Mídia e Cidadania, um espaço inédito em Goiás, destinado à promoção do debate sobre os conteúdos midiáticos. A análise da influência da mídia na construção da cidadania no Brasil é o objeto de estudo do observatório e do presente trabalho.
\end{abstract}

Palavras-chave: Mídia. Cidadania. Observatório.

\footnotetext{
Abstract

The media has a crucial role in the history of Brazilian society, while collective identities constructer. Through signs and signals, it builds and transforms images and realities. Indispensable to the achievement of the republic and the consolidation of capitalism, it challenges the scientific community interested in understanding its impact on society. In this process, the receiver is not just a passive spectator, but a critical user, that reframes the media messages. With the purpose of monitoring the media, reveal the relations

${ }^{1}$ Simone Antoniaci Tuzzo - Doutora em Comunicação pela Universidade Federal do Rio de Janeiro - UFRJ e professora adjunta da Universidade Federal de Goiás - UFG - Goiás. Pesquisadora permanente do Programa de Mestrado em Comunicação da UFG.

${ }^{2}$ Tiago Mainieri de Oliveira - Doutor em Ciências da Comunicação pela Universidade de São Paulo - USP e professor adjunto da Universidade Federal de Goiás - UFG. Pesquisador permanente do Programa de Mestrado em Comunicação da UFG.

${ }^{3}$ Magno Medeiros - Doutor em Ciências da Comunicação pela Universidade de São Paulo - USP e professor associado da Universidade Federal de Goiás - UFG - Goiás. Pesquisador permanente do Programa de Mestrado em Comunicação da UFG.

${ }^{4}$ Alunos mestrandos do Programa de Pós-Graduação em Comunicação da FACOMB/UFG.
} 
between it and society by promoting a dialogue between media and public sphere, students and teachers of Citizenship and Media Master's in Communication from Facomb / UFG created the Media Observatory and Citizenship, a inedited space in Goiás, for the promotion of discussion about media content. The analysis of media influence in the citizenship construction in Brazil is the study's object of the media observatory and of the present text.

Keywords: Citizenship. Media. Observatory.

\section{Introdução}

Jornal, rádio, televisão. Veículos de comunicação que têm como característica comum a informação em mão única. O que o leitor, o ouvinte e o telespectador recebem de informação vem de um padrão tradicional e controlador de emissão da notícia. No caso da internet, essa prática vem mudando, no entanto, vários são os sites provedores de conteúdo jornalístico que não têm uma participação ativa do internauta na produção jornalística.

É, por esses meios, que a população tem acesso aos fatos e acontecimentos que a rodeia. Muitas vezes essas informações são consumidas e digeridas sem uma reflexão ou um olhar crítico sobre o que a mídia nos impõe. Além disso, a notícia virou um produto à venda, de propriedade de poucos grupos que detêm o controle da mídia. Como veremos mais adiante neste artigo, no caso brasileiro, além da concentração da propriedade, o sistema de comunicação tem duas outras características: "[...] presença dominante de grupos familiares e vinculação com as elites políticas locais e ou regionais." (LIMA, 2001, p. 104).

Foi pensando na necessidade de abrir espaço para uma reflexão sobre a mídia e seus produtos que surgiu a proposta de construção do blog Observatório de Mídia, Cidadania e Poder. Este artigo tem como objetivo apresentar como o Observatório foi pensado e desenvolvido pelos alunos e professores da linha Mídia e Cidadania do Mestrado em Comunicação da Faculdade de Comunicação e Biblioteconomia da Universidade Federal de Goiás.

A chegada da internet abriu novas e muitas possibilidades na produção, emissão e recepção de informação e os blogs aparecem como um dos instrumentos mais utilizados para isso. O nome blog é uma contração do termo "web (página na internet) e log (diário de bordo). Borges (2007) define blog como “diários na Internet”, constituindo-se em páginas cuja atualização é rápida e feita em ordem cronológica inversa. Há blogs de várias temáticas escritos por uma ou várias pessoas. Eles surgiram com internautas contando passagens de suas vidas particulares e hoje se tornaram fonte de todo tipo de informação e opinião. São notícias, dicas, comentários, sugestões, dentre 
outros assuntos. Segundo Costa (2009), “[...] o objetivo de blogueiros e visitantes é veicular opinião".

Essa opinião necessariamente não é aquela construída pela massa, mas a opinião de públicos, já que ela surge justamente de grupos sociais como é o caso do Observatório de Mídia, Cidadania e Poder constituído de textos produzidos pelos alunos, professores e convidados do Mestrado de Mídia e Cidadania. Publicizar novos olhares sobre a mídia vai ao encontro do que Tuzzo (2005) aponta sobre opinião pública. É a partir dos grupos sociais com capacidade para pensar sobre assuntos relevantes para a coletividade, suas formas de interação e reflexão, e acima de tudo, sua capacidade de expressar a opinião que a opinião pública se forma. É uma opinião com força e capacidade de ser conhecida publicamente (TUZZO, 2005, p. 48).

No Brasil existem alguns blogs e sites cujo objetivo é a busca pelo senso crítico em relação aos produtos e mensagens produzidos e distribuídos pelos veículos de comunicação tradicionais. Em Goiás, a experiência do observatório se torna pioneira diante da falta de quaisquer outros meios de comunicação que estimulem uma contra-opinião, que possa colocar em questionamento a opinião formada a partir dos grandes veículos de comunicação.

\section{Mídia e percepção de mundo}

A comunicação é a ação de tornar comum uma ideia, ou ainda, uma ação que não se realiza sobre a matéria, mas sobre o outro (Temer, 2005, p. 276). Para Sodré (2006), a palavra comunicação recobre três campos semânticos: a veiculação, a vinculação e a cognição. A vinculação refere-se ao fato de que as informações veiculadas por certo meio de comunicação estão ligadas a determinadas ideias, refletidas na linha editorial, ao sistema organizacional e à determinada sociedade. Já a cognição é o modo como emissor e receptor apreendem uma informação.

Como argumenta Thompson (2001), com o advento da globalização e a transnacionalização das economias com trocas de informações e mercadorias em nível global, a comunicação passa a interferir de maneira mais forte na cognição, ou seja, na maneira como os seres humanos percebem o mundo. A mídia torna-se num quarto lugar de vida, o bios midiático diante da tecnocultura, como expõe Sodré. O que tanto Sodré (2006) como Thompson (2001) apontam é que a mídia, interface entre uma realidade específica e a sociedade, atua produzindo a percepção da realidade que o receptor/espectador forma do mundo. 
Desta forma, no contexto da sociedade pós-industrial, as relações entre os indivíduos são alteradas pela informação e conteúdo simbólico trazidos pela mídia. Criam-se novas formas de ação e interação no mundo social, novos tipos de relações sociais e do indivíduo com os outros e consigo mesmo (Thompson, 2001).

$\mathrm{Na}$ atualidade, a mídia torna-se o elemento constitutivo da identidade do receptor, processo que influencia na formação da cultura de diversos povos. Como é uma interface entre a sociedade e os acontecimentos, elementos e processos sociais, a mídia é também responsável pela cidadania, ou seja, pelo relacionamento dos cidadãos com o Estado. Devido à influência da mídia nos processos sociais, seria natural percebê-la como esfera pública, espaço fundamental para a discussão dos temas da sociedade civil referentes à consolidação da cidadania no Brasil.

Como já destacava Habermas (2003), o desenvolvimento da mídia é parte integral da formação das sociedades modernas. Segundo o autor, a circulação de matérias impressas, nos primórdios da Europa Moderna, teve um papel crucial na transição do absolutismo para os regimes liberais e democráticos, e a articulação da opinião pública, por meio da mídia, foi de grande importância para a vida democrática. No entanto, com a apropriação capitalista dos meios de comunicação, os objetivos comerciais impediram o debate crítico-racional na mídia, como espaço para a esfera pública. Passa-se do interesse público ao interesse comercial, à busca pelo lucro.

Neste contexto, o setor de comunicação passa por uma significativa mudança. De acordo com Lima, No cenário da globalização contemporânea, a consequiência mais evidente da convergência tecnológica no setor de comunicações é a enorme e sem precedentes concentração de propriedade (LIMA, 2001, p. 93).

Segundo o autor, esse novo padrão mundial faz surgir duas principais conseqüências, para quem a primeira é a fusão das diferentes políticas públicas-até então formuladas isoladamente para as áreas de telecomunicações, mass media e informática- em uma única política de comunicações; a segunda é a presença dos novos global players (conglomerados empresariais) e organismos internacionais (por exemplo: União Internacional de Telecomunicações-UIT, Organização Mundial do Comércio-OMC, etc.) como poderosos atores na formulação dessa política de comunicações, em nível tanto nacional como internacional (LIMA, 2001, p. 95).

Assim, percebemos que as mídias passam por mudanças e por processos de fusão e conglomerados, que acontecem a nível mundial, por uma dinâmica do mercado e pelo processo de globalização. 
Ainda de acordo com o autor, esse novo padrão de mídia, desenvolvido pelos conglomerados empresariais, encontra terreno fértil para se desenvolver no Brasil.

O padrão universal de concentração de propriedade e a presença dos globais players encontram no Brasil um ambiente historicamente acolhedor. Nossos mass media se estabeleceram oligopolisticamente. O rádio e a televisão continuam regidos por um código do início da década de 1960 (Lei 4117, de agosto de 1962) e constituem um sistema organizado em torno de poucas redes sobre as quais não existe nenhuma regulamentação legal. A propriedade e o controle das nossas telecomunicações, até recentemente monopólio do Estado, estão em processo de transferência para oligopólios privados, e a indústria de informática, depois de uma frustrada tentativa de reserva de mercado para as indústrias nacionais, consolida-se por meio da presença no mercado dos globais players da área. (LIMA, 2001, p. 97).

Além dessa característica de concentração de monopólios no setor de comunicação em escala mundial, o autor ressalta que no Brasil os sistemas de comunicações, historicamente, pertencem a grupos familiares e/ou são vinculados a elites políticas.

Antes da constituição de 1988, a decisão de concessões dos serviços de radiodifusão brasileira era exclusiva do presidente da república, e esse fato, de acordo com o autor, fez com que essa concessão fosse usada como moeda de troca e de favores políticos.

Para Lima, desse fato resultou a criação de um vínculo entre o setor de comunicações e a política, "o resultado é que o vínculo entre as comunicações e as elites políticas, sobretudo regionais e locais, deixou raízes profundas no país - e esta é uma característica que certamente vai existir ainda por muitos anos". (LIMA, 2001, p. 107).

A espetacularização da notícia é outro aspecto pertinente nessa discussão acerca da mídia. Não podemos esquecer que toda a encenação para transmitir a notícia tem o objetivo comercial. Vender a notícia passa necessariamente por torná-la atraente e de fácil interpretação.

Leal Filho ${ }^{5}$ expõe que a espetacularização pode ser fruto de uma combinação de fatores, sendo de um lado as necessidades comerciais e de outro o entretenimento que o público busca na televisão. As emissoras procuram o lucro para se manter - e por isso a realidade da publicidade; o receptor busca saber sobre o mundo enquanto se diverte.

\footnotetext{
${ }^{5}$ Laurindo Leal Filho em seu texto “As raízes da espetacularização da notícia” publicado no sítio Observatório da Imprensa <www.observatoriodaimprensa.com.br> fala dos fatores responsáveis pela espetacularização na mídia.
} 
Nesse sentido, pode-se citar o uso de gravações feitas por câmeras de segurança. No programa Domingo Espetacular da TV Record é raro um noticiário sem a presença de imagens captadas por câmeras não jornalísticas. O que desperta também duas análises, por um lado a democratização do jornalismo, que muitos chamam de Repórter Cidadão, e por outro o uso de imagens não autorizadas.

No ano de 2009, vários são os casos em que imagens de câmeras não vinculadas ao jornalismo profissional foram usadas para a composição de notícias. Tem-se o caso do desvio de verba pública por integrantes do governo de Brasília e o caso da estudante de Turismo que foi verbalmente agredida por mais de 700 estudantes por usar um vestido curto na Universidade.

Em ambos os casos, a mídia utilizou-se de imagens cedidas por câmeras não profissionais. Em Brasília, um dos envolvidos no esquema de corrupção, não satisfeito com a repartição dos recursos, usou uma câmera escondida para revelar o esquema. No caso da Universidade foram cenas feitas com a tecnologia de aparelhos celulares. As situações colocadas são relevantes para a sociedade, no entanto, a mídia tratou de espetacularizar a notícia.

A economia precisa da comunicação para fazer circular mercadorias e a comunicação precisa vender espaços publicitários para manter as empresas jornalísticas. A espetacularização garante socialmente o consumo e ainda a transmissão de informações.

Diante dessa realidade, destaca-se a importância de espaços para a discussão da mídia enquanto fenômeno social capaz de influenciar a percepção seja de indivíduos ou grupos sociais.

\section{Redes sociais e observatório da mídia}

A rede mundial de computadores surgiu durante a Guerra Fria com objetivos militares para manter a comunicação entre as forças armadas, vislumbrando a possibilidade de que bombardeios destruíssem os meios convencionais de telecomunicações. Nas décadas de 1970 e 1980, passou a ser utilizada como meio de comunicação acadêmico, e somente na década de 1990 Tim Bernes-Lee desenvolveu a World Wide Web. Com a utilização dessa interface gráfica e a criação de sites dinâmicos foi possível a expansão da internet no mundo.

Com a massificação da internet e a evolução das tecnologias da informação e comunicação, os computadores, celulares e mobiles passam a fazer parte do dia a dia das pessoas. Invadem e modificam o cotidiano social e possibilitam novos processos de interatividade, interação e circulação de informações de forma mais intensa e dinâmica. 
Tendo um computador e sinal de internet, podemos ter acesso a veículos de comunicação como jornal, rádio, telefone e programas de televisão.

No contexto da internet, ferramentas como mídias sociais passam a integrar o cotidiano das pessoas. Para Fragoso (2009), rede social é a união de dois elementos: pessoas, instituições ou grupos e suas interações ou laços sociais.

O número de "observatórios de mídia" tem crescido consideravelmente no Brasil e no mundo. Christofoletti e Motta (2008) explicam que universidades, administrações públicas locais, regionais, nacionais, além de entidades supranacionais e sindicatos vêm criando observatórios de variados tipos com o objetivo de fiscalizar os veículos de comunicação e seus profissionais e 'alfabetizar' midiaticamente o público.

Ao lançar um olhar atento aos meios, os observatórios apontam falhas técnicas, deslizes éticos e problemas de outras ordens. Coberturas tendenciosas são denunciadas, apurações mal feitas são destacadas, condutas condenáveis são apontadas. Mas fazer crítica de mídia não é apenas sublinhar o aspecto negativo, bons exemplos também devem ser enfatizados. (CHRISTOFOLETTI e MOTTA, 2008).

Os veículos de comunicação têm papel importante na difusão de símbolos, ideias e valores. O público reflete, adere ou descarta a influência dos meios. Por este motivo, o debate e a reflexão sobre a mídia são indispensáveis para que esses valores sejam analisados deforma cidadã.

Albornoz e Herschmann (2006) dividem os observatórios de mídia em duas categorias. Na primeira, são concebidos como espaços articuladores da cidadania a partir dos quais se pode monitorar o funcionamento dos meios de comunicação ("observatório fiscal").

A segunda os considera como organismos colaboradores por meio de suas intervenções e reflexões na formação de políticas públicas (“observatório think tank”). O Observatório da Mídia Regional da Universidade Federal de Pernambuco entende que, no Brasil, há uma terceira categorização que reúne as duas primeiras em um único observatório.

Em 2006, Albornoz e Herschmann investigaram os observatórios presentes no espaço iberoamericano. O estudo constatou a presença de 55 observatórios de diferentes tipos, estabelecidos nas principais cidades de onze países. A Espanha é o país que conta com mais observatórios, com 44\%; seguido do Brasil, com 13\%, e da Argentina, Colômbia e Uruguai, com 7\% cada um. Outros países somam 22\%. A maioria deles foi criada na segunda metade da década de 1990. 
Os autores acreditam que, de alguma maneira, os altos índices de concentração da propriedade dos meios de comunicação, relação simbiótica entre os meios de comunicação e poder político e crítica aos conteúdos oferecidos pelos sistemas mediáticos, motivaram a criação de observatórios nesta região.

A pesquisa revelou que os observatórios possuem três temáticas dominantes: avaliar as tendências das indústrias culturais e colaborar na formulação de políticas culturais (36\%); acompanhar o desenvolvimento da Sociedade da Informação e a implantação de novas tecnologias de informação e comunicação (33\%); e fiscalizar os conteúdos veiculados pelos meios de comunicação $(31 \%)$.

O estudo ainda mostrou que, entre os laboratórios pesquisados, 47\% têm atuação nacional, $38 \%$, nacional e 15\% internacional. Quase dois terços dos observatórios (69\%) são financiados com recursos públicos, $27 \%$ recebem dinheiro de organizações da sociedade civil e $4 \%$ apresentam financiamento misto.

A pesquisa não obteve respostas sobre as consequências da atuação dos observatórios no estímulo à leitura crítica da mídia pela sociedade. Diante disso, surgem algumas perguntas: em que medida os observatórios dos meios contribuem para cidadania e a democracia? O público, em sua maioria, consumidor da televisão e do rádio, tem acesso aos observatórios publicados especialmente na Internet? O conteúdo e a linguagem utilizada pelos observatórios são acessíveis e atrativos à sociedade?

As perguntas são muitas e, de acordo com os pesquisadores, só o tempo e o desenvolvimento destes observatórios poderá respondê-las. O fato é que, no momento, eles se apresentam como alternativa possível para o debate e a reflexão sobre os conteúdos e programas midiáticos e a promoção da cidadania.

\section{Metodologia - o Observatório de Mídia, Cidadania e Poder da UFG}

A pesquisa em Comunicação está intrinsecamente ligada aos produtos midiáticos, uma vez que o fazer comunicativo é também objeto de pesquisa desse campo. A universidade, portanto, está debruçada sobre as mídias, por vezes contradizendo-a, apontando falhas, desvelando processos e intenções. As análises são diversas: estuda-se a notícia em si, sua recepção, e até as relações institucionais e comerciais em meio a qual ela se estabelece. 
Contudo, se tais pesquisas e análises ficam restritas ao espaço acadêmico, não chegando ao conhecimento de quem produz a mídia ou mesmo da sociedade que a consome, todo esse esforço de gerar conhecimento parece, ao menos em parte, perder o sentido. Na expectativa de promover um espaço para circulação e debate das análises midiáticas oriundas de reflexões acadêmicas, professores e mestrandos da linha Mídia e Cidadania, do programa de Pós-graduação em Comunicação, Cultura e Cidadania (Facomb/UFG), decidiram organizar um observatório de mídia, cidadania e poder. As decisões acerca desse projeto foram realizadas em grupo, durante reuniões e aulas da disciplina ministrada conjuntamente pelos três professores que participam da autoria deste texto.

Optou-se por estruturar o Observatório em forma de blog, formato que privilegia e incentiva uma relação dialógica entre quem emite a mensagem e quem a recebe. Por meio da opção Comentário, os papeis de emissor e receptor se mesclam e se alternam, ainda que mantendo algumas hierarquias e relações de poder. Por exemplo, o fato do blogger poder excluir comentários ou editar o texto já postado, poderes que não são delegados também ao público que comenta. Mesmo assim, o blog se mostrou a ferramenta mais democrática e incentivadora do diálogo e da troca, razões pelas quais se adaptou melhor aos interesses do grupo e foi escolhida como plataforma para o desenvolvimento do Observatório.

O conteúdo a ser publicado no Observatório são reflexões de professores e alunos da linha, artigos de opinião produzidos nas disciplinas do mestrado, com temáticas que interligam as questões teóricas a aspectos práticos da vida e da cobertura midiática acerca dos fatos sociais. $\mathrm{O}$ grupo optou pelo artigo de opinião por se tratar do gênero textual que melhor se adapta ao meio de divulgação - ou seja, a internet - e à expectativa de trazer público para o debate. Nesse sentido, os textos são breves, escritos com linguagem acessível, sempre versando sobre temas de interesse público que receberam (ou deveriam ter recebido) destaque midiático.

Com a intenção de compreender os processos comunicacionais e contribuir para o aprimoramento da mídia goiana e brasileira, os textos discutem aspectos relevantes da vida social e sua cobertura, apontam questionamentos e caminhos. Além dos textos de professores e estudantes da linha, o espaço também vai contar com a participação de convidados que também possam acrescentar elementos significativos para o debate instaurado.

Problematizar, discutir e propor. É para isso que o grupo convida toda a sociedade a participar da análise midiática em questão. Alguns setores, porém, se identificam de forma mais 
próxima com o debate. Esse público vai fazer parte do mailing do Observatório, para o qual será enviada uma newsletter sempre que houver novas postagens no blog. Formam esse público, professores e estudantes das diferentes faculdades de comunicação no estado; jornalistas e demais representantes dos meios de comunicação; a classe política; professores de ensino fundamental e médio, que devem compreender a necessidade de incentivar seus alunos a uma leitura crítica das mídias.

Ainda com o propósito de agregar setores da sociedade a esse debate, o projeto também prevê a elaboração de estratégias visuais de comunicação como construção de logotipo e identidade gráfica, fatores que consolidem este Observatório.

Dessa forma, a proposta do observatório pretende estimular o hábito do espectador da mídia tornar-se também um analista crítico, capaz de pensar sobre as mensagens que consome.

\section{Conclusão}

A proposta de criação de um espaço para discutir a mídia é inovadora em Goiás. Como estudiosos e pesquisadores de comunicação, vimos a necessidade de publicizar nossos pensamentos e reflexões sobre os veículos de comunicação e seus produtos.

Numa época em que esses meios se tornam a "janela para o mundo" e a velocidade e a quantidade de informações é cada vez maior, o cidadão se torna um verdadeiro consumidor de informação, um cliente das empresas midiáticas.

O Observatório de Mídia, Cidadania e Poder não quer ser apenas um espaço para textos acadêmicos. A proposta é efetivamente contribuir e incentivar o cidadão a olhar criticamente a mídia, refletir sobre as informações que lhe chegam.

Sabemos que a exposição desses pensamentos no blog não vai gerar uma mudança de comportamento de todo o cidadão, e tão pouco atingir da mesma forma cada um deles, já que cada um formula sua opinião a partir do meio e da cultura em que vive. Mas esse é um primeiro passo, o começo de um projeto que pretende crescer com a contribuição de quem tem novos olhares sobre a mídia.

\section{Referências}

ALBORNOZ, Luís A; HERSCHMANN, Micael. Os observatórios ibero-americanos de informação, comunicação e cultura: balanço de uma breve trajetória. [S.1.], 2006. Disponível em: <http://www.compos.com.br/e-compos>. Acesso em: 31 jan. 2008. 
BARROS, Ana Paula Ferrari Lemos. A importância do conceito da esfera pública de Habermas para a análise da imprensa: uma revisão do tema. Disponível em:

<www.publicacoesacademicas.uniceub.br/index.php/> Acesso em: 17 dez. 2009.

BORGES, André. Blog: uma ferramenta para o jornalismo. In: Hipertexto Hipermídia: as novas ferramentas de comunicação digital. Ed. Contexto: São Paulo, 2007. p. 40-52.

CHRISTOFOLETTI, Rogério e MOTTA, Luiz Gonzaga. A cidadania se mobiliza para monitorar a mídia. Disponível em:

<http://www.informacao.andi.org.br/relAcademicas/site/visualizarConteudo.do?metodo=detalharN otic ia\&codigo=153> Acesso em: 13 jan. 2008.

COSTA, Alfredo José Lopes. Opinião e contraopinião no grand-monde da blogosfera. In: PINTO, Aroldo José Abreu; SOUZA, Shirlene Rohr de (Orgs.). Opinião na mídia contemporânea. São Paulo: Arte e Ciência, 2009. p.189-215.

CUNHA, Patrícia; REBOUÇAS, Edgard. Para que um Observatório de Mídia? Universidade Federal de Pernambuco. Disponível em:<www.ufpe.br/observatorio/relatorio.pdf> Acesso em: 20 out. 2010.

GUARESCHI, Pedrinho A.; BIZ, Osvaldo. Mídia, educação e cidadania: tudo o que você deve saber sobre mídia. Petrópolis, RJ: Vozes, 2005.

HABERMAS, Jürgen. Mudança estrutural da esfera pública: investigações quanto a uma categoria da sociedade burguesa. RJ: Tempo Brasileiro, 1984.

LIMA, Venício A. de. Mídia, teoria e política. São Paulo: Perseu Abramo, 2001.

THOMPSON, John B. A mídia e a modernidade: uma teoria social da mídia. Petrópolis, RJ:

Vozes, 2008.

TEMER, Ana Carolina. R. P. As bases sociológicas nos estudos das Teorias da Comunicação.

Comunicação. Veredas (UNIMAR), v. 4, p. 271-296, 2005.

TUZZO, Simone Antoniaci. Deslumbramento coletivo: opinião pública, mídia e universidade. São Paulo: Annablume, 2005. 